\title{
Pregnancy outcomes of mothers with immune thrombocytopenia
}

\author{
Shashikala Karanth ${ }^{1}$, Christy Vijay ${ }^{1 *}$, Chaitanya Harita ${ }^{2}$, Jaya S. Mol ${ }^{1}$
}

\begin{abstract}
${ }^{1}$ Department of Obstetrics and Gynecology, St. John's Medical College and Hospital, Bangalore, Karnataka, India ${ }^{2}$ Department of Medicine, St. John's Medical College and Hospital, Bangalore, Karnataka, India
\end{abstract}

Received: 21 August 2020

Accepted: 29 September 2020

\author{
*Correspondence: \\ Dr. ChristyVijay, \\ E-mail: christyvijay92@yahoo.in
}

Copyright: (c) the author(s), publisher and licensee Medip Academy. This is an open-access article distributed under the terms of the Creative Commons Attribution Non-Commercial License, which permits unrestricted non-commercial use, distribution, and reproduction in any medium, provided the original work is properly cited.

\begin{abstract}
Background: It has been proposed that, thrombocytopenia is the most common haematological abnormality in pregnancy after anaemia. The incidence of severe immune thrombocytopenia (ITP) in pregnancy has been difficult to report because of the rarity of the disease. Objectives were to determine the prevalence, pregnancy outcomes, treatment modalities of ITP mothers over five years in a tertiary health care hospital in South India.

Methods: Our study was a retrospective record study, which looked into various aspects of obstetrical outcomes and complications in ITP mothers. Records of the in-patient medical record department (MRD) folders of patients with ITP who delivered at St. Johns Medical Hospital, Bangalore were studied.

Results: We identified 53 patients with ITP with a mean age of $25.6+4.6$ years, age of diagnosis of ITP at $21.1+5.9$ years and gestational age of 36.2+3 weeks. In our study 17 (32\%) were acute and $36(67.1 \%)$ were chronic ITP. In our study $39.6 \%$ had history of at least one prior pregnancy loss. Patients with ITP at 35-37 weeks were induced with PGE1 (35.7\%) in comparison to those with PGE2 ( $\mathrm{p} \leq 0.001)$. Post-partum haemorrage (PPH) was seen in $7.5 \%$ of the pregnancies and all four were mothers with chronic ITP. Severe preeclampsia in ITP mothers was seen in $2(66.7 \%)$. Conclusions: Chronic ITP in pregnancy poses more risks to mother and foetus as seen with the higher chance of PPH etc. Mothers with ITP should be screened antenatally as the chances of anomalies are high in the foetus.
\end{abstract}

Keywords: ITP, APGAR score, Prednesolone, Platelettransfusion, Intrauterine device, Lower segment caesarean section

\section{INTRODUCTION}

Thrombocytopenia is the most common haematological abnormality in pregnancy, after anaemia. ${ }^{1}$ The incidence of severe immune thrombocytopenia (ITP) in pregnancy has been difficult to report because of the rarity of the disease, but reports have stated that its incidence ranges from 1 in 1000 to 1 in 10,000 pregnancies. ${ }^{2}$ The overall prevalence of thrombocytopenia in pregnancy is $7-10 \%$ and ITP contributes $3-4 \%$ to it. ${ }^{3,4}$ In ITP, maternal antibodies cross the placenta and damage platelet membrane glycoprotein. Although thrombocytopenia is a common finding in pregnancy, it can be life threatening to mother and foetus. ${ }^{3}$ Thrombocytopenia in pregnancy causes anxiety, not only to patients but also to clinicians. ${ }^{1}$ Available Information on the treatment protocols, risks (bleeding, post-partum haemorrhage, etc) and outcomes are not available for the Indian population. ${ }^{1}$ Diagnosis of ITP for the first time in pregnancy poses difficulties in the management of mother and foetus. ${ }^{4}$ Although many studies have looked into characteristics of predicting neonatal platelet count, there have been no correlations noted till date. ${ }^{4,5}$ One study stated the use of foetal scalp vein sampling or even percutaneous umbilical blood sampling to predict neonatal thrombocytopenia, of babies born of ITP mothers. ${ }^{6}$ The type of delivery, especially $\mathrm{C}$-section to prevent foetal intracranial haemorrhage and other outcomes have been questioned. ${ }^{6}$ 
ITP can be classified as Chronic and Acute ITP. ${ }^{7}$ Chronic ITP in adults is usually insidious onset, characterized by increased platelet destruction. ${ }^{7}$ Most patients rarely undergo a complete remission and require continuous therapy. ${ }^{7}$ Acute ITP usually occurs abruptly, commonly after a viral illness and platelet counts may recover spontaneously and high dose corticosteroids or intravenous gamma globulin therapy results in earlier recovery. ${ }^{7}$ As treating pregnancy associated with ITP can be difficult we aimed to study the obstetric outcomes and complications, outcomes of neonates born to immune thrombocytopenic mothers, and to look into various aspects and challenges faced with ITP in pregnancy.

\section{Objectives}

\section{Primary objective}

Primary objective of this study was to determine the prevalence of ITP in pregnant women who were admitted over the past five years in a Tertiary Health care hospital in South India.

\section{Secondary objective}

Secondary objective of this study was to assess the pregnancy outcomes of mothers with ITP in a tertiary health care hospital in South Indian population and to assess the various modalities of treatment given to mothers with ITP in a tertiary health care hospital in a South Indian population.

\section{METHODS}

\section{Sample size}

Our study was a retrospective record study, which looked into various aspects of obstetrical outcomes and complications of mothers with ITP. Records of all the InPatient medical record department (MRD) folders of patients with ITP who delivered in St. Johns Medical College and Hospital, Bangalore over 5 years (January 2015 to April 2020) were studied. Ethical approval and wavier of consent were taken prior to the start of the study, IEC Ref No.149/2020.

\section{Inclusion criteria}

Only cases where the diagnosis of ITP had been established based on standard criteria of thrombocytopenia associated with normal white and red blood cells were selected. We defined normal platelet count as $1,50,000 / \mathrm{ml}-4,00,000 / \mathrm{ml}$, mild thrombocytopenia as $1,00,000-150,000 / \mathrm{ml}$, moderate thrombocytopenia as $50,000-99,000 / \mathrm{ml}$ and severe thrombocytopenia as below $50,000 / \mathrm{ml}$ based on a study by Suri et al. ${ }^{4,8}$

Patients with acute and chronic ITP were included as per the Vicenza consensus conference and the criteria for differentiating primary from secondary forms of ITP was followed, with consideration of a new entity of ITP associated with the presence of antiphospholipid antibodies. $^{7,9}$

\section{Exclusion criteria}

Cases of other known causes of thrombocytopenia (gestational thrombocytopenia, infections etc.) were excluded.

Gestational thrombocytopenia was defined as a benign condition with moderate thrombocytopenia (platelet count of $1,30,000-1,50,000 / \mathrm{ml}$ ) as seen in most cases. ${ }^{10,11}$ Platelet values below $50,000 / \mathrm{ml}$ in a pregnant woman excluded gestational thrombocytopenia and further evaluation in search of another etiology was the dictum. ${ }^{10,11}$ It was a diagnosis of exclusion, with no maternal or fetal risks and with no response to steroids. ${ }^{10,11}$

Preeclampsia and HELLP syndrome induced thrombocytopenia was excluded. Preeclampsia is known to be the second most frequent cause of thrombocytopenia in second or third trimester, accounting for $21 \%$ of thrombocytopenia in pregnancy. ${ }^{11}$ It was defined by new onset hypertension with a systolic of $140 \mathrm{mmHg}$ and or $90 \mathrm{mmHg}$ diastolic blood pressure after 20 weeks of gestation along with proteinuria of 0.3 $\mathrm{g}$ in a 24-hour specimen. ${ }^{11}$ The impending signs of preeclampsia were observed and the diagnosis of eclampsia was made with the onset of seizures.11 Haemolysis resulting from red cell fragmentation usually accompanies severe preeclampsia was recorded. ${ }^{11}$

Criteria for the diagnosis of HELLP syndrome induced thrombocytopenia was as of those published by Sibai and included haemolysis (abnormal peripheral smear, LDH $600 \mathrm{U} / \mathrm{l}$, or bilirubin $1.2 \mathrm{mg} / \mathrm{dl}$ ), aspartate aminotransferase $70 \mathrm{U} / 1$, and a platelet count less than $1,00,000 / \mathrm{ml}^{11,12}$

B12 deficiency induced thrombocytopenia was defined as a deficiency in vitamin B12 which appears to be an inability to synthesize DNA in the blood cell precursors for orderly cell division and this affects all cell lines and eventually leads to thrombocytopenia. ${ }^{13}$ The peripheral smear would show a macrocytic blood picture and hyper segmented neutrophils, with greater than or equal to five lobes. ${ }^{13}$ B12 levels between 200 and $300 \mathrm{pg} / \mathrm{ml}$ were considered borderline and levels below $200 \mathrm{pg} / \mathrm{ml}$ were considered deficient. ${ }^{13}$

Infection related thrombocytopenia was defined as thrombocytopenia as an early manifestation of most septicemic bacterial, viral, or malarial infections. ${ }^{14}$ The possibility of the interaction of platelets with microorganisms as a defense mechanism was to be considered as a means to clear the infection from the circulation. ${ }^{14}$ 
Bacterial infections are known to cause consumptive thrombocytopenia by activation of coagulation cascade resulting in thrombin generation or direct interaction with platelets or immune-mediated destruction and platelet binding to subendothelial layers that have been exposed due to endothelial damage by the infectious agent. ${ }^{14}$

Viral thrombocytopenia was defined as decrease platelet production and increased platelet destruction due to direct platelet viral interaction. Immune mediated viral thrombocytopenia was also considered. ${ }^{14}$

The diagnostic criteria for sepsis was based on patients who presented with severe sepsis, and septic shock as per the surviving sepsis campaign guidelines. ${ }^{15,16}$ Thrombocytopenia in septic patients was defined as a peripheral blood platelet count less than $1,00,000 / \mathrm{ml}^{16}$

Drug induced thrombocytopenia was defined as patients who presented with a bleeding disorder caused by thrombocytopenia which was not associated with a systemic illness and which was based on a history of drug ingestion or injection and other biochemical laboratory findings. ${ }^{17}$ Thrombocytopenia with platelet count less than $50,000 / \mathrm{ml}$ and with spontaneous bleeding like simple ecchymoses, petechiae, mucosal bleeding, life threatening intracranial hemorrhage with drug use was considered. ${ }^{17}$ Exclusion of other causes such as congenital disorders and inflammatory processes, recurrence of thrombocytopenia after second exposure to a drug was noted. ${ }^{17}$ Laboratory investigation such as total blood count and platelet serology tests were also studied to differentiate drug induced thrombocytopenia from other causes. ${ }^{17}$ Other causes of thrombocytopenia such as congenital or inherited platelet disorders, other immune mediated thrombocytopenia etc. were excluded based on the guidelined by Gernsheimer et al. ${ }^{11}$

\section{Maternal variables}

Development of any new symptoms like bleeding manifestations during pregnancy like petechae, purpura etc. was noted. Platelet count of the mother at admission and discharge, pregnancy outcomes like need for induction of labor, mode of delivery (normal vaginal or cesarean delivery) was recorded. Complications like PPH (post-partum hemorrhage), (intensive care unit) (ICU) admission of the mother, severe preeclampsia etc, were studied. Treatment of patients during the antenatal, intrapartum and postnatal period was also studied.

\section{Fetal variables}

Neonatal outcomes like APGAR, complications at birth, were studied. neonatal parameters like birth weight, preterm births, placental weight, singleton or twin gestation, congenital anomalies in fetus etc. was noted. In our Institution we monitored the babies for platelets at 6 24 hours and till the platelet count was is on a increasing trend before discharge. Treatment would be based on the platelet counts

\section{Variables related with ITP}

Treatment at initial diagnosis, type of steroids and other medications used for treatment of ITP was studied. Complication of steroid toxicity (steroid induced hyperglycemia, need for other alternative treatment due to steroid overdose, Cushing's syndrome like features etc.) need for intrapartum blood and blood product transfusion due to thrombocytopenia was studied.

\section{Institution protocols}

No interaction with patient was made and strict confidentiality of records was maintained. The monitoring in the charts included a strict institutionalized partograph. Vigilant monitoring of blood loss during vaginal delivery or LSCS was recorded in the MRD folders, which was done by quantifying the blood loss at time of delivery and platelet count as described by Baucom et al. ${ }^{8}$

Our institution protocols were in accordance with the guidelines of Gernsheimer et al, all patients in the first and second trimesters who presented with platelet counts $<30,000 / \mathrm{ml}$ were treated and therapy at a later gestational date was generally based on the risk of maternal hemorrhage at delivery. ${ }^{11}$ The platelet count was assessed monthly during routine antenatal checkups. ${ }^{11}$ The frequency of platelet monitoring was done weekly from 34 weeks of gestation. ${ }^{11}$ Prednisolone $10 \mathrm{mg}$ once daily starting 10 days before the anticipated date of delivery was a treatment option received. ${ }^{11}$ Women with no bleeding manifestations and platelet counts above $30,000 / \mathrm{ml}$ were not treated until delivery was imminent. ${ }^{11}$ If platelet was less than $30,000 / \mathrm{ml}$ patient was started on corticosteroids or platelet transfusion based on the clinical scenario. ${ }^{11}$ Doses were adjusted to maintain platelet count more than $30,000 / \mathrm{ml}$ and never exceed 30 mg. ${ }^{11}$ The complication in management ITP after antenatal corticosteroids was documented. As per the NICE guideline all diabetic mothers who received steroids had been treated with additional insulin along with diet and regular glycemic monitoring during the period. ${ }^{19}$

\section{Analysis}

Data was analyzed using the SPSS versions 16 after it was manually entered in Micro Soft Excel. Inter-quartile ranges were deduced for variables such as gestational age, age of diagnosis, platelet count etc. for analysis of pregnancy outcomes in ITP mothers. The Pearson's Chi Square, Fishers exact was used as the test for significance. 


\section{RESULTS}

\section{General population characteristics}

We identified 53 pregnant mothers with ITP over a period of 5 years with a mean age of $25.6+4.6$ years, mean age of diagnosis of ITP at $21.1+5.9$ years and mean gestational age of $36.2+3$ weeks at the time of delivery.

\section{Obstetric outcomes}

Out of the 53 patients most patients were primigravida 35 $(66 \%)$ and $6(11.3 \%)$ were unbooked. Bad obstetric history was seen commonly in chronic ITP 6 (16.7\%). It was seen that severe preeclampsia $9(16.98 \%)$ was the most common complication of pregnancy.

Severe preeclampsia in immune thrombocytopenic mothers was seen in two patients $(66.7 \%)$ who were aged $>35$ years, in comparison to the seven pregnant women $<35$ years $(14 \%, \mathrm{p}=0.061)$. Grandmultigravida had a significant history of a past intrauterine dead fetus (IUD) $2(40 \%, \mathrm{p}=0.003 \mathrm{~b})$ compared to multigravida 3 (23.1). History of prior abortion $3(60 \%, \mathrm{p}<0.001 \mathrm{~b})$, higher chance of receiving packed cell transfusion as a mode of treatment $4(80 \%, p=0.021 b)$ for excessive bleeding, chance of delivery of IUGR babies 2 (40\%, 0.001b) was significantly high, in grandmultigravida compared to primigravida. Primigravida were treated with prednesolone $30(85.7 \%, \quad \mathrm{p}=0.018 \mathrm{~b})$ compared to multigravida $6(46.2 \%)$. Patients with ITP at 35-37 weeks were induced with misoprostol $(35.7 \%)$ in comparison to those induced with dinoprostone $(\mathrm{p} \leq 0.001)$. Out of the 53 subjects $10(1.88 \%)$ delivered spontaneously, $22(41.5 \%)$ were induced, $2(3.7 \%)$ underwent elective LSCS, while $26(49 \%)$ underwent emergency LSCS. All LSCSs were done on obstetric indications. PPH was seen in $7.5 \%$ of the pregnancies, where in 1 was a full-term vaginal delivery $(>500 \mathrm{ml})$, one was a preterm delivery $(>1000 \mathrm{ml})$, and two were emergency LSCS $(>1000 \mathrm{ml})$ and all four were mothers with chronic ITP.

\section{Neonatal outcomes}

Total of $29(54.7 \%)$ male and $25(47.1 \%)$ female babies were born. One pregnancy was a Dichorionic diamniotic twin gestation. Out of the 53 deliveries, 21 (39.6\%) were low birth weight and one was an extremely preterm delivery less than 28 weeks of gestation. APGAR scores were less than 5 in $7(13.2 \%)$ of the deliveries which gradually improved over five minutes to over $90 \%$ scoring $>8$, due to timely and effective neonatal resuscitation protocols. Placenta weight reached more than $500 \mathrm{~g}$ even in early gestation $(32 \%, \mathrm{p}=0.017)$. Mothers with ITP at $28+1-33+6$ weeks who delivered very preterm babies had mild anaemia 2 (40\%, $\mathrm{p}=0.002 \mathrm{~b})$, oligohydramnios $1 \quad(20 \%, \mathrm{p}=0.020 \mathrm{~b})$, cholestasis of pregnancy $2(40 \%, \mathrm{p}=0.006 \mathrm{~b})$, ARDS 1 $(20 \%, p=0.020 b)$ which were significant results.

\section{Outcomes as a result of ITP}

In our study $17(32 \%)$ were newly diagnosed ITP and 36 $(67.1 \%)$ were chronic ITP and $34(64.1 \%)$ of the subjects with chronic ITP were on treatment for the same. Chronic ITP patients were noticed to lose more blood $>1000 \mathrm{ml}$ when compared to acute Immune thrombocytopenic mothers. The most common treatment in the subjects of our study were platelet transfusion, which was more frequently used in acute ITP (82.4\%) in comparison to chronic ITP, due to its acute demand at the time of pregnancy. Prednesolone was the most commonly used steroid in both acute $(82.3 \%)$ and chronic (72.2\%) ITP, followed by dexamethasone; $76.5 \%$ of acute and $52.8 \%$ of chronic ITP. This was due to institutional protocols of overlap of dexamethasone and prednesolone as described earlier. Packed cell transfusion was given for severe bleeding. About 26 (49.1\%) mothers received platelet transfusion intrapartum. About half of the study subjects (49\%) had severe thrombocytopenia at admission and although most of these subjects did improve with treatment, $28.3 \%$ were discharged with platelet count less than $49,000 / \mathrm{ml}$, as the treatment of ITP is a ongoing and gradual process, and rising platelet trend from previous values ,even if less than $49,000 / \mathrm{ml}$ is sufficient for patients to get discharged on post-natal day 3 or postoperative day 4 as per our institutional protocols, with regular monthly follow up to the haematology department. Steroid toxicity was seen in 7 (13.2\%) subjects, which was the second most commonly encountered complication in these pregnancies, presenting in both groups of acute $2(11.8 \%)$ and chronic ITP 5 (13.9\%). Patients diagnosed with ITP at ages 11-18 years of age were treated frequently with azathioprine 8 $(61.5 \%, \mathrm{p}=0.015 \mathrm{~b})$, had higher chance of ICU admission $2(15.4 \%, \mathrm{p}=0.041 \mathrm{~b})$ and large placenta weight $>500 \mathrm{~g} 8$ $(61.5 \%, 0.002 b)$. About $26(49.1 \%)$ mothers received platelet transfusion intrapartum.

\section{Exceptions}

One 33-year-old multigravida, diagnosed with ITP at 12 years of age delivered a $300 \mathrm{~g}$ baby at 20 weeks of gestation, with a platelet count at admission $27,000 / \mathrm{ml}$ and at discharge $32,000 / \mathrm{ml}$.

She received prednisolone, platelet transfusion and dexamethasone during her pregnancy. Another case which was diagnosed at 4 years of age with ITP delivered a baby with co-arctation of aorta $(\mathrm{p}<0.001 \mathrm{~b})$, she had received hydrocortisone and prednesolone during the antenatal period.

We noticed most patients were primigravida $35(66 \%)$. It was seen that severe preeclampsia $9(16.98 \%)$ was the most common complication of pregnancy, followed by steroid toxicity $7(13.2 \%)$ (Table 1$)$.

Placenta weight reached more than $500 \mathrm{~g}$ even in early gestation of 29-37 weeks (32\%, p=0.017) (Table 2). 
Table 1: Demography of pregnant mothers with ITP.

\begin{tabular}{|ll|}
\hline Obstetric score & N $(\%)$ \\
\hline Primigravida & $35(66)$ \\
\hline Multigravida & $13(24.5)$ \\
\hline Grandmultigravida & $5(9.4)$ \\
\hline History of prior pregnancy loss & \\
\hline 1 abortions & $12(22.6)$ \\
\hline 2 abortions & $3(5.6)$ \\
\hline 3 abortions & $2(3.7)$ \\
\hline 4 abortions & $2(3.7)$ \\
\hline Ectopic pregnancy & $1(1.8)$ \\
\hline Intrauterine foetal demise & $5(9.4)$ \\
\hline Complication of pregnancy with ITP & \\
\hline ANA & $5(9.4)$ \\
\hline APLA & $1(1.88)$ \\
\hline SLE & $1(1.88)$ \\
\hline Status post splenectomy & $2(3.77)$ \\
\hline Steroid toxicity & $7(13.2)$ \\
\hline Severe Preeclampsia & $9(16.98)$ \\
\hline IUGR & $2(3.77)$ \\
\hline Antepartum haemorrhage & $1(1.88)$ \\
\hline
\end{tabular}

In Table 3 changes in parameters in pregnancy with ITP. Most patients had a very low platelet count at the time of admission 26 (49\%) of less than 49,000/ml, and postdelivery at discharge had platelet count of nearly normal levels 17 (32\%). Chronic ITP patients were known to lose more blood $>1000 \mathrm{ml}$ when compared to acute ITP mothers.

Neonatal out comes as predicted by APGAR scores in ITP pregnancies. APGAR scores were less than 5 in $13.2 \%$ of the deliveries which gradually improved over five minutes as seen, with over $90 \%$ scoring $>8$, due to timely and good neonatal resuscitation (Table 4).
Treatment received by ITP mothers. Mothers with acute and chronic ITP were treated more commonly with platelet transfusion $38(71.6 \%)$ and Prednesolone 40 (75.4\%) (Table 5).

Table 3: Changes in parameters in pregnancy with ITP.

\begin{tabular}{|llll|}
\hline Variable & $\begin{array}{l}\text { Platelet at } \\
\text { admission }\end{array}$ & $\begin{array}{l}\text { Platelet at discharge } \\
\text { N (\%) }\end{array}$ & $\mathbf{N}(\%)$ \\
\hline Platelet count & & & \\
\hline$<49000$ & $26(49.0)$ & $15(28.3)$ & \\
\hline $\mathbf{5 0 0 0 0 - 9 9 , 9 9 9}$ & $7(13.3)$ & $11(20.7)$ & \\
\hline $\mathbf{1 - 1 . 5}$ Lakhs & $9(16.9)$ & $17(32.0)$ & \\
\hline$>1.5$ Lakhs & $11(20.7)$ & $10(18.8)$ & \\
\hline $\begin{array}{l}\text { Blood loss at } \\
\text { delivery }\end{array}$ & $<500 \mathrm{ml}$ & $\begin{array}{l}500-1000 \\
\mathrm{ml}\end{array}$ & $>1000$ \\
\hline $\begin{array}{l}\text { Acute Immune } \\
\text { Thrombocyto } \\
\text { penia }\end{array}$ & $11(68.8)$ & $5(31.2)$ & $0(0)$ \\
\hline $\begin{array}{l}\text { Chronic Immune } \\
\text { Thrombocyto } \\
\text { penia }\end{array}$ & $25(69.4)$ & $8(22.2)$ & $3(8.3)$ \\
\hline
\end{tabular}

Table 4: Neonatal out comes as predicted by APGAR scores in ITP.

\begin{tabular}{|lll|}
\hline Variables & $\mathbf{1}$ minute & $\mathbf{5}$ minute \\
\hline APGAR score & $\mathbf{N}(\boldsymbol{\%})$ & $\mathbf{N}(\boldsymbol{\%})$ \\
\hline$<\mathbf{5}$ & $7(13.2)$ & $1(1.9)$ \\
\hline $\mathbf{6 - 7}$ & $16(30.2)$ & $4(7.5)$ \\
\hline$>\mathbf{8}$ & $30(56.6)$ & $48(90.6)$ \\
\hline
\end{tabular}

Table 2: Gestational age and pregnancy outcomes.

\begin{tabular}{|c|c|c|c|c|c|c|c|}
\hline \multirow{2}{*}{$\begin{array}{l}\text { Gestational age } \\
\text { (weeks) }\end{array}$} & \multirow{2}{*}{$\mathbf{N}$} & \multicolumn{6}{|l|}{ Placenta weight } \\
\hline & & $<250 \mathrm{~g}$ & $251-500 \mathrm{~g}$ & \multicolumn{2}{|c|}{$>500 \mathrm{~g}$} & \multicolumn{2}{|l|}{$P$ value } \\
\hline$<28$ & 1 & $1(100)$ & $0(0)$ & \multicolumn{2}{|c|}{$(0)$} & \multirow{4}{*}{$0.017^{b}$} & \\
\hline $28+1-33+6$ & 5 & $1(20)$ & $1(20)$ & 3( & & & \\
\hline $34-36+6$ & 28 & $2(7.1)$ & $12(42.9)$ & 14 & 50) & & \\
\hline \multirow[t]{3}{*}{$37+1-42$} & 19 & $0(0)$ & $8(42.1)$ & 11 & $57.9)$ & & \\
\hline & \multicolumn{3}{|c|}{ Mode of delivery } & & & & \\
\hline & $\mathbf{N}$ & $\begin{array}{l}\text { Extreme } \\
\text { preterm delivery }\end{array}$ & $\begin{array}{l}\text { FTVD/ } \\
\text { RMLE }\end{array}$ & $\begin{array}{l}\text { FT } \\
\text { Forceps }\end{array}$ & $\begin{array}{l}\text { PTVD/ } \\
\text { RMLE }\end{array}$ & $\begin{array}{l}\text { Emergency } \\
\text { LSCS }\end{array}$ & $\begin{array}{l}\text { Elective } \\
\text { LSCS }\end{array}$ \\
\hline$<28$ & 1 & $1(1.8)$ & $0(0)$ & $0(0)$ & $0(0)$ & $0(0)$ & $0(0)$ \\
\hline $28+1-33+6$ & 5 & $0(0)$ & $0(0)$ & $0(0)$ & $3(5.6)$ & $2(3.7)$ & 0 \\
\hline $34-36+6$ & 28 & $0(0)$ & $5(9.4)$ & $1(1.8)$ & $5(9.4)$ & $17(32.0)$ & 0 \\
\hline $37+1-42$ & 19 & $0(0)$ & $10(18.8)$ & $0(0)$ & $0(0)$ & $7(13.2)$ & $2(3.7)$ \\
\hline
\end{tabular}

$\mathrm{a}=$ Chi-Square; $\mathrm{b}=$ Fisher's Exact; *statistically significant at $\alpha=5 \%$ and $\mathrm{p}<0.05$. Placenta weight reached more than $500 \mathrm{~g}$ even in early gestation of 29-37weeks (32\%, p=0.017). FTVD/RMLE: Full term vaginal delivery with right mediolateral episiotomy, FT Forceps: Full term forceps delivery, PTVD/RMLE: preterm vaginal delivery with right mediolateral episiotomy 
Table 5: Treatment received by ITP mothers.

\begin{tabular}{|llllllllll|} 
Variables & $\mathbf{N}$ & $\begin{array}{l}\text { Platelet } \\
\text { trans- } \\
\text { fusion }\end{array}$ & $\begin{array}{l}\text { Packed } \\
\text { cells } \\
\text { trans- } \\
\text { fusion }\end{array}$ & $\begin{array}{l}\text { Fresh frozen } \\
\text { plasma } \\
\text { transfusion }\end{array}$ & $\begin{array}{l}\text { Hydroxy- } \\
\text { chloroquine } \\
\text { (HCQ) }\end{array}$ & $\begin{array}{l}\text { Pre- } \\
\text { dneso- } \\
\text { lone }\end{array}$ & $\begin{array}{l}\text { Dexa- } \\
\text { metha- } \\
\text { sone }\end{array}$ & $\begin{array}{l}\text { Hyrocort } \\
\text { isone }\end{array}$ & $\begin{array}{l}\text { Aza- } \\
\text { thio- } \\
\text { prine }\end{array}$ \\
\hline & $\mathrm{N}(\%)$ & $\mathrm{N}(\%)$ & $\mathrm{N}(\%)$ & $\mathrm{N}(\%)$ & $\mathrm{N}(\%)$ & $\mathrm{N}(\%)$ & $\mathrm{N}(\%)$ & $\mathrm{N}(\%)$ & $\mathrm{N}(\%)$ \\
\hline $\begin{array}{l}\text { Acute } \\
\text { ITP }\end{array}$ & 17 & 14 & 2 & 2 & 1 & 14 & 13 & 1 & 4 \\
\hline $\begin{array}{l}\text { Chronic } \\
\text { ITP }\end{array}$ & $(32.1)$ & $(82.4)$ & $(11.8)$ & $(11.8)$ & $(5.9)$ & $(82.3)$ & $(76.5)$ & $(5.9)$ & $(23.5)$ \\
\hline
\end{tabular}

\section{DISCUSSION}

There is no reliable maternal parameter to predict the susceptibility and the need for intervention in mothers with life threatening thrombocytopenia and the complications it poses to the foetus. ${ }^{20}$ Hence, constant vigilance is required in establishing a safe pregnancy outcome in mothers with ITP.

The mean age of diagnosis of ITP was 19.32 years in a study on 107 pregnancies with ITP in 202 UK hospitals. 2 In another study on 446 pregnancies over a period of 16 years in the USA, the mean age of pregnancy was $30.3+$ 5.3 years. $^{21}$ Our study showed pregnant mothers with mean age $25.6+4.6$ years and mean age of diagnosis of ITP at $21.1+5.9$ years. Won et al studied 30 women with ITP with a mean gestational age of 36.5 weeks.22 Our study showed the mean gestation age of 36.2 weeks.

In our study $39.6 \%$ had history of at least one prior pregnancy loss (abortion or IUD). Patients with ITP at 35-37 weeks of gestation were induced with misoprostol $(35.7 \%)$ in comparison to those induced with dinoprostone $(p \leq 0.001)$. The probability of ITP in pregnancy to be a triggering factor for preterm labour, PPROM, increased chance of early effacement of cervix or the use of steroids to reduce immunity with increased susceptibility toinfections (chorioamnitis)are to be considered.

In our study $47.3 \%$ had a normal vaginal delivery, $49 \%$ had undergone an emergency LSCS and $3.7 \%$ had an elective LSCS. In a study group in Netherlands, where pregnancies were complicated with foetal and neonatal allo-ITP, had achieved $72 \%$ normal vaginal delivery rate with no evidence of intracranial haemorrhage in any of the neonates, showing the benefits of vaginal delivery. ${ }^{23}$ Yassaee et al however felt caesarean section was beneficial as $85 \%$ of the patients underwent caesarean section with low platelet count. ${ }^{6}$

Complications like PPH was seen in $7.5 \%$ of the pregnancies, and all four were mothers with chronic ITP. Other complications like intra operative wound hematoma was seen in $1.8 \%$ of the subjects, $3.7 \%$ had an ICU admission. Varying results were seen in a study by Care et al with rate of PPH as high as $52 \%$, while no subjects had wound hematoma or ICU admission. ${ }^{2}$ Almost twice the rate of PPH (12.5\%) was noticed by a French study in comparison to our study. ${ }^{24}$

A study showed $81.2 \%$ of the subjects with ITP in pregnancy to have a live birth and $17.9 \%$ of these babies had low birth weight.21 In our study $98.1 \%$ had a live born baby and $37.7 \%$ had low birth babies. Placenta weight reached more than $500 \mathrm{~g}$ even in early gestation of $29-37$ weeks $(32 \%, p=0.017)$, possibility of the effect of steroid use in pregnancy.

In comparison to our study findings with a mean APGAR of 7 at 1 minute and 8 at 5 minutes another study with mean gestateonal age of 38 weeks and birth weight 2.9 $\mathrm{kgs}$ had APGAR scores $>8.25$

Wyszynski et al notice at least one major malformation in $7.8 \%$ of pregnancies with ITP, $2.9 \%$ has osetiumsecundum ASD, $5.3 \%$ hypospadiasis, $1.7 \%$ PDA. ${ }^{21}$ Our study had $1.8 \%$ of pregnancies with facial dysmorphism and $1.8 \%$ with coarctation of aorta in foetus $(\mathrm{p}<0.001 \mathrm{~b})$. The study went on to state that cardiac anomalies are three times more likely in foetuses born to mothers with ITP, possibily due to steroid use early in pregnancy. ${ }^{21}$ Another meta-analysis indicates a 3. 4-fold increase in risk of oral cleft among infants with first trimester exposure to steroids. ${ }^{11}$

One study stated that over investigation and excessive treatment of maternal thrombocytopenia to be avoided unless platelet falls $<50,000 / \mathrm{ml}$ and caesarean section to be done only for obstetric indications. ${ }^{26}$ In our hospital we treated patients with platelet transfusion if delivery was anticipated, with protocol cut offs $50,000 / \mathrm{ml}$ for normal vaginal delivery and $70,000 / \mathrm{ml}$ for caesarean section and all LSCS were done for obstetric indications.

Won et al showed a mean platelet count of $62,680 / \mathrm{ml}$ at delivery in the pregnant mothers of his study. ${ }^{22}$ The mean platelet count at the time of admission and discharge from the hospital was $88090 / \mathrm{ml}$ and $96660 / \mathrm{ml}$ respectively. Mean platelet count at delivery was $92,375 / \mathrm{ml}$. Won et al observed a falling trend in platelet count in the third trimester, wherein $61.3 \%$ women received platelet transfusion. ${ }^{22}$ The patients of our study 
received platelet transfusions for acute $(82.4 \%)$ and chronic $(66.7 \%)$ ITP in pregnancy.

We observed prednesolone $(75.4 \%)$ to be the most commonly use corticosteroid, followed by dexamethasone $(60.3 \%)$ and azathioprine (30.1\%).The study findings by Yassaee et al showed similar results of corticosteroids to be main source of treatment $(61.5 \%){ }^{6}$ Care et al contradicted our findings that $79 \%$ of severe ITP pregnancies were given only IVIG (20\%), combined corticosteroids and IVIG (32\%) and anti D injections. ${ }^{2}$ No patient received IVIG, Anti D, Rituzimab, Romiplostim for the treatment of ITP pregnancy. ${ }^{24,27,28}$

Our study showed patient with ITP and ANA positive 5 (9.4\%), APLA positive $1(1.88 \%)$ and SLE 1 (1.88\%). A recent study stated that an isolated positive ANA test in low titres does not contradict the probability of primary ITP, even if there is a different response to corticosteroid therapy. ${ }^{9}$ The study stated that the condition may progress with the increasing amount of ANA and other antibodies such as anti-ds DNA, anti-Sm and antinuclear ribonucleoprotein antibodies and a progressive spreading of autoimmunity may take place, from organ and nonorgan specific antibodies, explaining the above results in our study. ${ }^{9}$

\section{Limitations}

Post intervention analysis could not be performed.

\section{CONCLUSION}

Chronic ITP in pregnancy poses more risks to mother and foetus as seen with the higher chance of PPH etc. Mothers with ITP should be screened antenatally as the chances of anomalies are high in the foetus. Prior bad obstetric history in ITP mothers should predict the outcomes of the present pregnancy. Platelet transfusion continues to still remain as the gold standard for treatment of ITP. Close monitoring of antenatal period with regular platelet values increases the chance of a good outcome of the present pregnancy in ITP mothers especially those with chronic ITP.

One among the first few papers where the outcomes of pregnancy in ITP mothers have been studied in detail and observed various treatment options in and Indian setting. Scope for the Future: Maternal and Child Health Mission should accentuate the need for consideration of a separate scheme for ITP mothers, with incentives to relieve burden of illness on mothers and their families.

\section{ACKNOWLEDGMENTS}

The study team remains grateful to the Doctors, postgraduates, interns and nursing staff of Department of Obstetrics and Gynaecology of St. John's Medical College, Bangalore, Karnataka.
Funding: No funding sources

Conflict of interest: None declared

Ethical approval: The study was approved by the Institutional Ethics Committee

\section{REFERENCES}

1. Gilmore KS, McLintock C. Maternal and fetal outcomes of primary ITP during pregnancy: A retrospective study. Obstet Medic, 2018;11(1):12-6.

2. Care A, Pavord S, Knight M, Alfirevic Z. Severe primary autoITP in pregnancy: a national cohort study. Int J Obstet Gynaecol. 2018;125(5):604-12.

3. Melekoğlu NA, Bay A, Aktekin EH, Yilmaz M, Sivasli E. Neonatal outcomes of pregnancy with ITP. Ind J Hematol Bloo Transfus. 2017;33(2):211-5.

4. Suri V, Aggarwal N, Saxena S, Malhotra P, Varma S. Maternal and perinatal outcome in idiopathic thrombocytopenic purpura (ITP) with pregnancy. Acta obstetricia et gynecolo Scandina. 2006;85(12):1430-5.

5. Özkan H, Cetinkaya M, Köksal N, Ali R, Güneş AM, Baytan B, et al. Neonatal outcomes of pregnancy complicated by idiopathic thrombocytopenic purpura. J Perinatol. 2010;30(1):38-44.

6. Yassaee F, Eskandari R, Amiri Z. Pregnancy outcomes in women with idiopathic thrombocytopenic purpura. Irani J Reproduct Medic. 2012;10(5):489-92.

7. Blanchette S. Glycoproteins in Children Purpura. 2012;5(5):1600-2.

8. Algadiem EA, Ali Algadiem E, Aleisa AA, Alsubaie HI, Buhlaiqah NR, Algadeeb JB, et al. Blood Loss Estimation Using Gauze Visual Analogue. Trauma Mon. 2016;21(2):e34131

9. Alberto M. Marmont; Antinuclear antibody (ANA)positive thrombocytopenia: primary, but with a difference. Bloo. 2009;114(9):2003-4.

10. Perepu U, Rosenstein L. Maternal thrombocytopenia in pregnancy. Proc Obstet Gynecol. 2013;10;3(1):15.

11. Gernsheimer T, James AH, Stasi R. How I Treat How I treat thrombocytopenia in pregnancy Establishing the cause of thrombocytopenia. Bloo. 2013;121(1):38-47

12. Sibai BM. Evaluation and management of severe preeclampsia before 34 weeks' gestation. Am J Obstet Gynecol. 2011;205(3):191-8.

13. Ankar A, Kumar A. Vitamin B12 Deficiency (Cobalamin). Available at: https://www.ncbi.nlm. nih.gov/books/NBK441923/. Accessed on 20 May 2020.

14. Wilson JJ, Neame PB, Kelton JG. Infection-induced thrombocytopenia. Semin Thromb Hemost. 1982;8(3):217-33.

15. Dellinger RP, Levy MM, Rhodes A. Surviving Sepsis Campaign: international guidelines for management of severe sepsis and septic shock, 2012. Intensive Care Med. 2013;39:165-228. 
16. Li MF, Li XL, Fan KL. Platelet desialylation is a novel mechanism and a therapeutic target in thrombocytopenia during sepsis: an open-label, multicenter, randomized controlled trial. J Hematol Oncol. 2017;10(1):104.

17. Visentin GP, Liu CY. Drug-induced thrombocytopenia. Hematol Oncol Clin North Am. 2013;39:165-228.

18. Baucom, AM, Kuller JA, Dotters-Katz S. Immune thrombocytopenic purpura in pregnancy. Obstetric Gynecol Surv. 2019;74(8):490-6.

19. Kalra S, Kalra B, Gupta Y. Glycemic management after antenatal corticosteroid therapy. N Am J Med Sci. 2014;6(2):71-6.

20. Jaegtvik S, Husebekk A, Aune B, Øian P, Dahl LB, Skogen B. Neonatal alloITP due to anti-HPA 1a antibodies; the level of maternal antibodies predicts the severity of thrombocytopenia in the newborn. Int J Obstet Gynaecol. 2000;107(5):691-4.

21. Wyszynski DF, Carman WJ, Cantor AB, Graham JM, Kunz LH, Slavotinek AM, et al. Pregnancy and birth outcomes among women with idiopathic thrombocytopenic purpura. J Pregnan. 2016;2016.

22. Won YW, Moon W, Yun YS, Oh HS, Choi JH, Lee YY, et al. Clinical aspects of pregnancy and delivery in patients with chronic idiopathic thrombocytopenic purpura (ITP). Kore J Intern Medic. 2005;20(2):129.

23. De Haan TR, Van Den Akker ES, Porcelijn L, Oepkes D, Kroes AC, Walther FJ.
Thrombocytopenia in hydropic fetuses with parvovirus B19 infection: incidence, treatment and correlation with fetal B19 viral load. Int J Obtet Gynaecol. 2008;115(1):76-81.

24. Comont, T. Re: Severe Primary AutoITP (ITP) in Pregnancy: a national cohort study Primary ITP management during pregnancy. Int $\mathrm{J}$ Obstet Gynaecol. 125(5):629-30.

25. Michel M, Novoa MV, Bussel JB. Intravenous anti$\mathrm{D}$ as a treatment for immune thrombocytopenic purpura (ITP) during pregnancy. British journal of haematology. 2003;123(1):142-6.

26. Greave M, Letsky EA. Guidelines on the investigation and management of thrombocytopenia in pregnancy and neonatal alloITP. Int $\mathbf{J}$ Obstet Gynaecol, 1997;104(10):1108.

27. Browning J, James D. ITP in pregnancy', Fetal and Maternal Medicine Review, 1999;2(2):143-57.

28. Patil AS. Use of a thrombopoietin mimetic for chronic immune thrombocytopenic purpura in pregnancy. Obstetrics and Gynecology. 2013;122(2) 483-5.

Cite this article as: Karanth S, Vijay C, Harita C, Mol JS. Pregnancy outcomes of mothers with ITP (ITP). Int J Reprod Contracept Obstet Gynecol 2020;9:4535-42. 